\title{
Mutagenicidade do naftaleno através do teste do micronúcleo: estudo em modelo animal (Astyanax altiparanae) e vegetal (Tradescantia pallida purpurea)
}

Os hidrocarbonetos Aromáticos Policíclicos, como o Naftaleno, são considerados poluentes orgânicos prioritários em estudos ambientais. Alguns apresentam elevado potencial de toxicidade e podem ser precursores de efeitos mutagênicos e carcinogênicos. $O$ teste de micronúcleo é uma ferramenta sensível na detecção de eventos clastogênicos e aneugênicos ocasionados por xenobióticos. 0 objetivo deste trabalho foi avaliar a mutagenicidade do naftaleno após exposição aguda em um modelo animal e um vegetal. Os bioindicadores foram a espécie de peixe Astyanax altiparanae e a planta Tradescantia pallida purpurea. No teste de micronúcleo písceo nenhum dos tratamentos apresentou diferença significativa com o controle negativo. No teste em células-mãe do grão de pólen de Tradescantia a concentração de 0,3 mgL- 1 apresentou mais micronúcleos em relação ao controle negativo. O Trad-MCN demonstrou maior sensibilidade na detecção de quebras e perdas cromossômicas ocasionadas pelo naftaleno.

Palavras-chave: Bioensaios; Ecotoxicologia; Mutagênese Ambiental; Teste do Micronúcleo; Célula-Mãe do Grão de Pólen.

\section{Naphthalene mutagenicity through micronucleus test: animal (Astyanax altiparanae) and vegetal study model (Tradescantia pallid purpurea)}

\footnotetext{
The Polycyclic Aromatic Hydrocarbons, such as naphthalene, are considered priority organic pollutants in environmental studies. Some have high potential for toxicity and can be precursors of mutagenic and carcinogenic effects. The micronucleus test is a sensitive assay to detect aneugenic and clastogenic events caused by xenobiotics. The aim of this study was to assess the mutagenicity of naphthalene after acute exposure in an animal and vegetable model. The sentinels were the fish species Astyanax altiparanae and the plant Tradescantia pallid purpurea. Piscine micronucleus test (fish's erythrocyte) showed no significant difference with the negative control. In the test using pollen mother-cell of Tradescantia the concentration of $0.3 \mathrm{mg} \mathrm{L}-1$ of naphthalene showed a higher micronuclei frequency compared to the negative control. The Trad-MCN demonstrated greater sensitivity for the detection of chromosomal breakage and loss caused by naphthalene.
}

Keywords: Bioassays; Ecotoxicology; Environmental Mutagenesis; Micronucleus Test; Pollen-Mother-Cell.

Topic: Química Agrícola e Ambiental

Reviewed anonymously in the process of blind peer.

Geonildo Rodrigo Disner

Universidade Federal do Paraná, Brasil

http://lattes.cnpq.br/0195399532696728

disner.rodrigo@gmail.com

\section{Marta Margarete Cestari}

Universidade Federal de São Carlos, Brasil

http://lattes.cnpq.br/0507218392616237

margaces@ufpr.br

DOI: 10.6008/SPC2179-6858.2016.002.0001
Received: 05/01/2016

Approved: 10/04/2016
Referencing this:

DISNER, G. R.; CESTARI, M. M.. Mutagenicidade do naftaleno através do teste do micronúcleo: estudo em modelo animal (Astyanax altiparanae) e vegetal (Tradescantia pallida purpurea). Revista IberoAmericana de Ciências Ambientais, v.7, n.2, p.6-15, 2016. DOI: http://doi.org/10.6008/SPC2179-6858.2016.002.0001 


\section{INTRODUÇÃO}

Os Hidrocarbonetos Policíclicos Aromáticos (HPAs) são compostos químicos constituídos unicamente de átomos de carbono e hidrogênio, arranjados em dois ou mais aneis de benzeno ligados de forma linear ou aglomerada (POTIN et al., 2004). São considerados poluentes orgânicos prioritários em estudos ambientais (BRUSICK et al., 2008). Alguns compostos dessa classe apresentam elevado potencial de toxicidade, podem ser precursores de efeitos mutagênicos e carcinogênicos, além de apresentarem alta persistência ambiental (IARC, 2002; MEIRE et al., 2007). Devido à possibilidade de fusão de um número variável de aneis e em diversas posições que podem se ligar, há atualmente mais de 100 HPAs reconhecidos pela International Union of Pure Applied Chemistry (IUPAC), porém somente 16 são prioritariamente considerados em função de sua importância industrial, ambiental e toxicológica, dentre eles o Naftaleno (POTIN et al., 2004; MEIRE et al., 2007).

A produção de HPAs ocorre naturalmente ou por processos industriais. Fontes naturais incluem incêndios florestais, escoamento de petróleo, vulcões e produção por organismos vivos (DUNBAR et al., 2001). Entretanto, são as fontes antropogênicas que predominam a entrada desses compostos na natureza. As maiores emissões são oriundas da exaustão de motores movidos a combustíveis fósseis em geral; além de processos industriais ligados à produção de aço e alumínio, plástico, borrachas sintéticas, fibras, fertilizantes, a partir de derramamentos de petróleo, descargas dos navios, da exaustão de incineradores de rejeito e efluentes industriais (WRIGHT; WELBOURN, 2002). Estes compostos podem ser distribuídos nos mais variados compartimentos ambientais como ambiente aquático, solo e atmosfera. Em contrapartida a degradação ambiental de HPAs pode se dar por processos físico-químicos, como, por exemplo, degradação por foto-oxidação, ou pela ação biológica de microrganismos (HWANG et al., 2002).

O naftaleno é um dos compostos mais intensivamente estudados dentre os HPAs devido à sua alta toxicidade, baixa sensibilidade à foto-oxidação e baixo peso molecular (VIJAYAVEL et al., 2004). Apresentase como um hidrocarboneto aromático bicíclico, sendo derivado do alcatrão ou a partir de óleo cru (PUBLIC HEALTH SERVICE, 2010; BISCHOFF, 2004). É considerado pouco solúvel em água e altamente volátil (MEIRE et al., 2007). Acredita-se que o naftaleno esteja entre os principais responsáveis pela toxicidade aguda do óleo cru. Este contém aproximadamente 1,5\% de HPAs, dos quais o naftaleno é o principal componente, perfazendo 65\% da constituição de HPAs totais (TRUSCOTT et al., 1992).

O naftaleno tem sido utilizado, principalmente nos Estados Unidos, para produção de plástico, corante, resinas, lubrificantes, combustíveis, e como pesticida, principalmente no controle de traças em áreas de estocagem (IARC, 2002). É um poluente onipresente introduzido no ambiente aquático principalmente através de processos de produção e destilação de produtos do carvão, bem como subprodutos de petróleo e por derramamentos deste (PACHECO et al., 2001).

O impacto do naftaleno em humanos e outros animais tem sido objeto de pesquisas. Entretanto, um número limitado de estudos vem sendo conduzidos para avaliar a toxicidade do naftaleno em ambientes 
aquáticos, tendo em vista que este é o receptáculo da maioria dos contaminantes e através deste meio muitos indivíduos podem ser expostos.

O teste do micronúcleo (TMN) é um dos ensaios in vivo mais utilizados para a detecção de agentes clastogênicos (que quebram cromossomos) e aneugênicos (que induzem aneuploidia ou segregação cromossômica anormal). Os cromossomos ou fragmentos que resultam de quebras podem não ser incorporados ao núcleo principal das células filhas após a mitose, então uma membrana nuclear se formará em volta do fragmento, o qual será visível como um pequeno núcleo separado do núcleo principal da célula (RIBEIRO, 2003). O TMN tem sido usado com sucesso como um ensaio de mutagenicidade devido ao fato de ser simples, confiável, sensível e independente de características cariotípicas (AL-SABTI et al., 1995).

A espécie de peixe Astyanax altiparanae Garutti \& Britski, conhecida popularmente como lambari, pertencente à família Characidae está enquadrada em um gênero conhecido por não realizar migração e possuir papel central na cadeia trófica (SCHULZ et al., 2001), além de apresentar ampla distribuição em rios e córregos das bacias brasileiras. São peixes de pequeno porte, atingem em média $10 \mathrm{~cm}$ de comprimento padrão e apresentam grande flexibilidade alimentar, ingerindo principalmente insetos e sementes (BENNEMANN et al., 2002), servindo também como importante fonte alimentar para peixes carnívoros (PRIOLI et al., 2002). O método que utiliza especificamente eritrócitos de peixes para o TMN é rápido e pode ser feito sem causar nenhum sofrimento ao animal. Por essas razões, o teste em peixes, chamado teste de micronúcleo písceo (TMNP), é um ensaio adequado para investigação da mutagenicidade ambiental (ALSABTI et al., 1995).

A Tradescantia pallida cv. purpurea (Rose) Hunt. é uma planta herbácea da família Commelinaceae adaptada a quase todos os ambientes, crescendo todo o ano em regiões subtropicais. Possui um tamanho relativamente pequeno (menor de $50 \mathrm{~cm}$ de altura) e seis pares de grandes cromossomos em suas células somáticas tornando-a um favorável bioindicador para estudos citogenéticos (MA, 1981; SAVÓIA et al., 2009). A Tradescantia é uma espécie prolífica, robusta e ramificada que se tornou um popular material de experimentação citogenética desde o final da década de 30. Extensivos estudos dos efeitos diretos e indiretos da radiação sobre cromossomos mitóticos dessa planta contribuíram para a base do conhecimento dos princípios da quebra cromossômica induzida por radiação (MA, 1981). O teste do micronúcleo em Tradescantia (Trad-MCN) consiste em um conjunto de procedimentos de exposição de plantas deste gênero a agentes tóxicos que culmina com a estimativa da frequência de micronúcleos em células-mãe dos grãos de pólen na fase de tétrade (ANDRADE JUNIOR et al., 2008). Nesse contexto, o objetivo deste trabalho foi avaliar o potencial do Naftaleno em causar quebras e/ou perdas cromossômicas, em dois modelos comparativos, um peixe (Astyanax altiparanae) e uma planta (Tradescantia pallida purpurea).

\section{METODOLOGIA}

\section{Preparação da Solução de Naftaleno}


Para cada uma das concentrações foi preparada uma solução estoque com naftaleno (CAS n. 91-203) diluído no solvente etanol. As soluções foram feitas nas concentrações de 0,005; 0,03; 0,3 e $3 \mathrm{gL}^{-1}$, desse modo o volume do contaminante e consequentemente do solvente foram os mesmo em todos os tratamentos e compatíveis com o respectivo controle.

\section{Teste do Micronúcleo Písceo (TMNP)}

Foram utilizados peixes da espécie Astyanax altiparanae de ambos os sexos, saudáveis e em fase juvenil, obtidos em piscicultura comercial. Os animais foram aclimatados em tanques de 2.000 litros, sob temperatura média de 25ํㅡ, por 30 dias antes do início do experimento. Em seguida, foram transferidos para aquários de 20 litros e mantidos sob temperatura $( \pm 25$ 을 $)$ e aeração constante, fotoperíodo $12 / 12$ horas claro/escuro, onde ocorreu a exposição ao naftaleno. Cada grupo amostral consistiu em 15 indivíduos de $A$. altiparanae expostos às concentrações de naftaleno de 0,$005 ; 0,03 ; 0,3$ e $3 \mathrm{mgL}^{-1}$; dois controles negativos, um mantido apenas em água e outro com etanol. O tempo de exposição foi de 96 horas, em sistema semiestático com renovação diária de dois terços da água e do contaminante. Outro grupo recebeu uma injeção intraperitoneal de metil-metano sulfonado (MMS) um dia antes do sacrifício, na concentração de $5 \mathrm{mgkg}^{-1}$ com a finalidade de controle positivo. Decorrido o tempo de exposição os peixes foram anestesiados com benzocaína a 10\% (GONTIJO et al., 2003), foram tomadas as medidas morfológicas e então os peixes foram sacrificados para retirada de amostras de sangue. Os procedimentos experimentais realizados neste trabalho estão de acordo com os princípios éticos estabelecidos para experimentação animal, aprovados pela comissão de ética no uso animal (CEUA) da Universidade Federal do Paraná sob o protocolo 724/2013.

O teste para análise de micronúcleos em eritrócitos foi baseado na metodologia proposta por Heddle (1973) e Schmid (1975), com coloração por laranja de acridina proposta por UEDA et al., (1992). Uma gota de sangue foi pingada em uma lâmina de microscopia sendo feito um esfregaço para cada animal. Foram analisados 2000 eritrócitos por lâmina em microscópio de fluorescência.

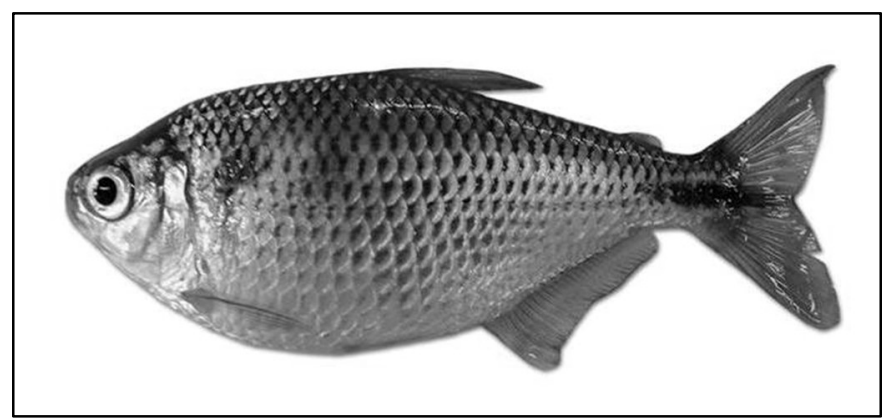

Figura 1: Exemplar de Astyanax altiparanae Garutti \& Britski.

\section{Teste de Micronúcleo em Tradescantia (Trad- MCN)}

Os experimentos foram realizados com inflorescências coletadas de uma população homogênea de Tradescantia pallida purpurea. As inflorescências juvenis foram aclimatadas em água destilada por 24 horas e em seguida expostas as diferentes concentrações de naftaleno: 0,005; 0,03; 0,3 e $3 \mathrm{mgL}^{-1}$ pelo período de 
10 horas, através da imersão do escapo das inflorescências na solução com o contaminante. Além dos expostos, foram feitos os controles negativo, controle solvente (etanol) e controle positivo (metil-metano sulfonado-MMS, $\left.10 \mathrm{mgL}^{-1}\right)$. A exposição foi em sistema semi-estático, havendo uma renovação de $100 \%$ da água com o contaminante para garantir uma maior manutenção da concentração inicial. Além disso, em função de tratar-se de composto volátil, os recipientes onde permaneceram as inflorescências foram cobertos com plástico-filme. Decorrida a exposição, as inflorescências foram transferidas para recipientes com água destiladas por mais 24 horas para uma fase de recuperação. Os botões florais em formação foram fixados em carnoy (etanol/ácido acético 3:1) por 24 horas e depois transferidos para estocagem em frascos com etanol 70\%. Para a montagem das lâminas os botões foram dissecados com estilete sobre uma lâmina de microscopia e as anteras jovens contendo células mãe do grão de pólen no estágio de tétrades foram maceradas sobre a lâmina com uma gota de carmim acético 2\% e cobertas com lamínula. Foram feitas 10 lâminas por tratamento e em cada lâmina foram analisadas 300 tétrades em microscópio óptico.

\section{Análise Estatística}

Para análise estatística dos resultados primeiramente foi aplicado o teste de normalidade Kolmogorov-Smirnov. Tendo os dados apresentado distribuição anormal, aplicou-se o teste não-paramétrico Kruskal-Wallis seguido do Student-Newman-Keuls, para comparar tratamentos entre si. Dados com distribuição normal utilizou-se ANOVA para comparar os grupos. Para todas as análises foi considerado significativo o $p<0,05$. O pacote estatístico empregado foi BioEstat 5.0.

\section{RESULTADOS}

O peso médio dos peixes utilizados no estudo foi de 5,60 gramas e o comprimento médio de 7,73 centímetros. Não houve mortalidade durante o experimento. Quanto a contagem de micronúcleos em eritrócitos de $A$. altiparanae a estatística não mostrou diferença entre os grupos em relação ao controle em nenhuma das concentrações testadas. As frequências de danos cromossômicos, observada pela formação de micronúcleos, foram baixas nos peixes.

Já a frequência de micronúcleos encontrados em tétrades de Tradescantia pallida expostas ao naftaleno apresentou diferença com o controle negativo apenas na concentração de $0,3 \mathrm{mgL}^{-1}$.

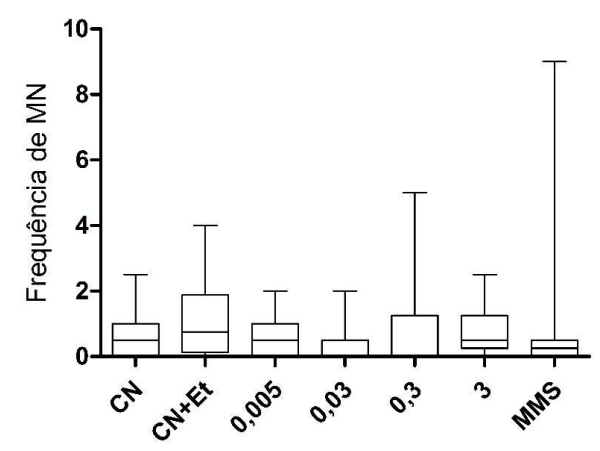

Gráfico 1: Frequência de micronúcleos (MN) encontrados em eritrócitos de Astyanax altiparanae após exposição aguda a diferentes concentrações de naftaleno $\left(\mathrm{mgL}^{-1}\right)$, controle negativo, controle solvente (etanol) e positivo $5 \mathrm{mgkg}$

${ }^{1}$. Não houve diferença significativa entre os tratamentos, $p<0,05$. 


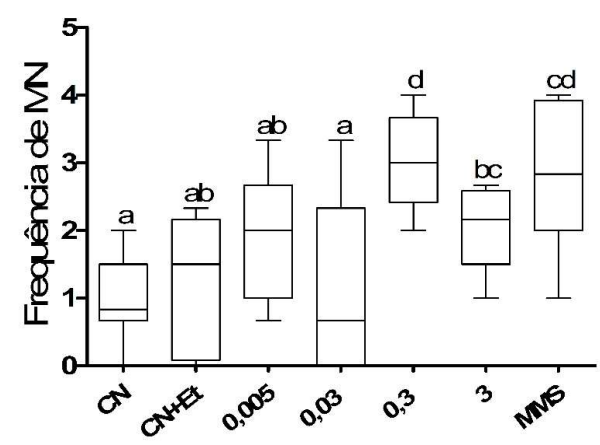

Gráfico 2: Frequência de micronúcleos (MN) encontrados em células-mãe do grão de pólen de Tradescantia pallida purpurea após exposição aguda a diferentes concentrações de naftaleno $\left(\mathrm{mgL}^{-1}\right)$, controle negativo, controle solvente (etanol) e positivo $10 \mathrm{mgL}^{-1}$. Letras diferentes indicam diferença significativa, $\mathrm{p}<0,05$.

\section{DISCUSSÃO}

A globalização e os processos industriais contemporâneos relacionados a esta provocam intensos impactos no ambiente. No meio aquático, em especial, o aumento da poluição por hidrocarbonetos aromáticos tem sido relevante desde o início da exploração do petróleo. Ecossistemas aquáticos geralmente são os principais receptores de resíduos industriais e urbanos, assim o estudo dos efeitos de poluentes nestes locais é de grande interesse, principalmente pelo fato da estreita relação à exposição humana direta, seja pelo consumo de água ou organismos contaminados. Além disso, o ambiente aquático apresenta ampla biodiversidade e existem muitas populações de organismos, como peixes, microcrustáceos e plâncton, que podem ser afetadas negativamente em decorrência de substâncias xenobióticas lançadas nesses habitats.

O naftaleno é o principal HPA presente em óleo cru, petróleo e seus derivados, e devido à sua ampla dispersão torna-se um dos mais importantes em estudos dessa natureza. No experimento deste trabalho optou-se por testar baixas concentrações de naftaleno, menores que às presentes em ambientes com histórico ou que apresentam contaminação. Alguns trabalhos relatam que, em geral, as populações dos peixes podem ser expostas no ecossistema aquático à uma concentração total do HPA variando de 50 a 410 $\mathrm{mgL}^{-1}$ (KAYAL et al., 1989; SMITH et al., 1991). Desta forma, o estudo torna-se mais realista em relação ao ambiente natural, tendo em vista que a proporção de naftaleno presente no meio pode variar muito. 0 naftaleno é pouco estável e as características do ambiente como o volume do corpo d'água, sua movimentação, temperatura, entre outras, geralmente tendem a diminuir ainda mais a quantidade de naftaleno biodisponível. Por isso foram escolhidas quatro diferentes concentrações, para ampliar a gama de representação de possíveis situações de contaminação ambiental.

O teste de micronúcleo (TMN) é um dos ensaios mais utilizados para detecção de mutagenicidade pela ocorrência de quebras e perdas cromossômicas. Neste trabalho, quando utilizou-se o peixe como organismo bioindicador, não foram observadas diferenças na contagem de $\mathrm{MN}$, bem como de outras anormalidades morfológicas nucleares entre os grupos tratados e controles.Isso deve-se, principalmente, porque apenas células em divisão celular podem potencialmente apresentar micronúcleo (FENECH, 2000), e peixes em geral apresentam baixo índice hematopoiético e seus eritrócitos podem permanecer em circulação por tempos que variam de 60 a 160 dias dependendo da espécie utilizada nos bioensaios (TAVARES et al., 
2004). Assim, devido ao experimento ter sido conduzido por 96 horas é provável que poucos eritrócitos tenham sido produzidos durante o período experimental, justificando as poucas anormalidades e ausência de $\mathrm{MN}$ encontradas.

Esta sugestão é corroborada por diversos estudos, nos quais a exposição dos peixes foi aguda e os pesquisadores não encontraram aumento relevante na frequência de $\mathrm{MN}$ nos grupos expostos aos xenobióticos. Como por exemplo, experimentos realizados por Disner e colaboradores (2011) com A. altiparanae expostos ao Roundup ", e de Ghisi et al. (2013) utilizando Corydoras paleatus também expostos ao Roundup ${ }^{\circ}$, não encontrou diferenças significativas entre os grupos controle e expostos. Winter e colaboradores (2007) com Pimephales promelas expostos a ciclofosfamida e Bücker e colaboradores (2006) avaliando benzeno em peixes elétricos (Eingenmannia virescens) também não observaram indução de $\mathrm{MN}$. Desse modo, o teste MNP deve ser prioritariamente utilizado para estudos de exposição sub-crônica ou crônica.

Outras evidências parecem suportar a ideia de que o naftaleno é rapidamente eliminado dos organismos e do ambiente experimental de exposição, assim, o dano resultante geralmente é reduzido em função da baixa permanência do organismo em contato com o contaminante. Eisele (1985) realizou um trabalho onde galinhas foram expostas via gavagem ao naftaleno por 31 dias, cessada a exposição e decorridas 48 horas após este evento, os animais já haviam eliminado entre $75-80 \%$ do composto, demonstrando uma baixa permanência deste agente no indivíduo. Varanasi et al. (1978) de forma similar observaram grande perda do contaminante pelo organismo em curto espaço de tempo. Tais pesquisadores expuseram truta-arco-irís (Oncorhynchus mykiss) ao naftaleno e verificaram que após 96 horas grande parte do composto havia sido eliminada, sendo o muco epidérmico sugerido como principal via de excreção. Do mesmo modo, Melancon e Lech (1978) relataram uma meia-vida do naftaleno e do metil-naftaleno nos tecidos de truta-arco-íris como sendo menor que 24 horas, exceto em gorduras. Estes pesquisadores, usando dados de eliminação do ${ }^{14} \mathrm{C}$-naftaleno, puderam distinguir a eliminação após exposições agudas ou crônicas, sendo que, devido à metabolização do composto que ocorre geralmente em exposições crônicas, a perda dáse mais lentamente.

Em um estudo de Melancon et al. (1978) a acumulação e eliminação do ${ }^{14} \mathrm{C}$ em tecidos de truta-arcoíris depois de exposição ao ${ }^{14} \mathrm{C}$-naftaleno ou ${ }^{14} \mathrm{C}$-2-metil-naftaleno foi investigado. Após oito horas de contato a 0,005 ou $0,023 \mathrm{mg} / \mathrm{L}$ de ${ }^{14} \mathrm{C}$-naftaleno, os tecidos dos alevinos estudados continham de 20 a 100 vezes mais ${ }^{14} \mathrm{C}$ que os níveis da água, enquanto gordura e bile continha um aumento excedente a centenas de vezes mais que a água, que se deve basicamente pela natureza lipofílica dos HPAs. Como observado pelos pesquisadores, o naftaleno foi rapidamente absorvido, logo após o início da exposição. Desta forma, este estudo dá embasamento ao método de exposição (via hídrica) utilizado e não deixa dúvidas que o naftaleno é biodisponibilizado aos organismos antes mesmo que sofra degradação.

Já o teste Trad-MCN em células mãe do grão de pólen de Tradescantia pallida purpurea apresentou maior sensibilidade de deteç̧ão da mutagenicidade do naftaleno. A técnica para observação de MN naturalmente se mostrou mais eficiente e com maior suscetibilidade pois tanto o controle negativo quanto 
positivo apresentaram baixa e elevada frequência de $\mathrm{MN}$, respectivamente. Quanto aos tratamentos verificou-se que a concentração de 0,3 $\mathrm{mgL}^{-1}$ de naftaleno aumentou significativamente a frequência de micronúcleos, sendo que não foi verificado dano dose dependente.

Isso deve-se, especialmente, porque cromossomos meióticos são mais suscetíveis a quebras que cromossomos mitóticos. É apontado que a frequência de micronúcleos no ensaio Trad-MCN é maior em estágios iniciais da formação do pólen e os micronúcleos formados podem ser incorporados nas células de grãos de pólen maduras, que formarão os esporos. Isso sugere que os micronúcleos podem ser resultantes de cromossomos atrasados ou cromossomos não pareados e que não foram incorporados na célula-filha.

O ensaio tem alta sensibilidade e simplicidade para execução. Além disso, uma vantagem adicional do ensaio Trad-MCN é o curto período necessário de exposição para completar o teste, apenas 6-10 horas, seguido por 24 horas de período de recuperação para permitir que as células tratadas em prófase alcancem o estágio de tétrade.Talvez o principal aspecto do ensaio seja a capacidade de detecção de baixos níveis de genotoxicidade (em baixas concentrações) ou em exposições agudas (RODRIGUES et al., 1997).

Diversos estudos têm aplicado o Trad-MCN em inflorescências de Tradescantia para monitorar riscos ambientais, obtendo resultados satisfatórios por meio destes. A exemplo da exposição ao ozônio (LIMA et al., 2009), poluição do ar (GUIMARÃES et al., 2000; SANTOS, 2015) e naftaleno (ALVES et al., 2008). Neste último, os pesquisadores observaram um aumento significativo na frequência de micronúcleos após exposição das inflorescências ao naftaleno sólido (ALVES et al., 2008).

Um aspecto peculiarmente interessante no teste Trad-MCN é a plasticidade em que a planta pode ser utilizada. As inflorescências de Tradescantia podem ser usadas tanto para monitoramento da água quando de vapores e qualidade do ar (indoor e outdoor). No nosso estudo o uso deste teste foi importante pois os HPAs, e em especial o naftaleno, são altamente voláteis, durante a exposição é provável que se utilizando o modelo vegetal mais vias de exposição sejam exploradas. As principais vantagens do Trad-MCN são a facilidade na execução dos procedimentos, eficácia na avaliação de dano cromossômico, rápida execução, fácil cultivo e propagação das plantas e, em divisão meiótica, os cromossomos são mais sensíveis aos agentes químicos e físicos.

As inflorescências jovens são as mais indicadas, pois tem tétrades em botões de estágio intermediário. A tétrade está na fase de interfase, e sua duração vai de 36 à 48 horas.

\section{CONCLUSÃO}

O teste de micronúcleo mostrou-se efetivo na análise da mutagenicidade do naftaleno, embora o modelo vegetal (Trad-MCN) tenha sido mais sensível na deteç̧ão de perdas e quebras cromossômicas. 0 naftaleno apresentou efeito mutagênico por meio do teste Trad-MCN na concentração de $0,3 \mathrm{mgL}^{-1}$. O teste de micronúcleo písceo é um teste rotineiro em avaliações ambientais, porém conforme foi verificado neste estudo é necessário um maior tempo de exposição para que as alterações possam ser observadas nas células animais. 
A adoção de um bioindicador sensível a concentrações baixas de xenóbióticos é importante em estudos de mutagênese ambiental, pois expressam danos citogenéticos iniciais, fornecendo importantes informações sobre a saúde e qualidade ambiental.

Sugere-se, sempre que possível, a adoção de diferentes modelos de estudos a fim de monitorar cautelosamente os perigos causados pelos compostos químicos liberados no ambiente, além de gerar importantes dados comparativos entre espécies, sendo que quanto mais modelos de estudos forem utilizados com maior segurança pode-se extrapolar os achados para outras espécies, inclusive a humana.

\section{REFERÊNCIAS}

AL-SABTI, K.; METCALFE, C.D.. Fish micronuclei for assessing genotoxicity in water. Mutation Research, v.343, p.121-135, 1995.

ALVES, E.S.; SOUZA, S.R.; PEDROSO, A.N.V.; DOMINGOS, M.. Potential of the Tras-MCN assay applied with inflorescences of Tradescantia pallid 'Purpurea' for evaluating air contamination by naphthalene. Ecotoxicology and Environmental Safety, v.71, p.717-721, 2008.

ANDRADE JR, S.J.; SANTOS JR, J.C.S.; OLIVEIRA, J.L.; CERQUEIRA, E.M.M.; MEIRELES, J.R.C.. Micronúcleos em tétrades de Tradescantia pallida purpúrea Boom: alterações genéticas decorrentes da poluição aérea urbana. Acta Scientiarum Biological Sciences, Maringá, v.30, n.3, p.295301, 2008

BENNEMANN, S. T.; SHIBATTA, A. O.. Dinâmica de uma assembleia de peixes do rio Tibagi. In: MEDRI, M. E., BIANCHINI, E.; SHIBATTA, O. A.; PIMENTA, J. A.. A Bacia do Rio Tibagi. Londrina: Edição dos Editores, 2002.

BISCHOFF, N,. Naphthalene. Clinical veterinary toxicology. Mosby: St Louis, 2004.

BRUSICK, D.; SMALL, M. S.; CAVALIERI, E. L.; CHAKRAVARTI, D.; DING, X.; LONGFELLOW, D. G.; NAKAMURA, J.; ROGAN, E. C.; SWENBERG, J. A.. Possible genotoxic models of action for naphthalene. Regulatory Toxicology and Pharmacology, v.51, p.43-50, 2008.

BÜCKER, A.; CARVALHO, W.; ALVES-GOMES, J. A.. Avaliação da mutagênese e genotoxicidade em Eigenmannia virescens (Teleostei: Gymnotiformes) expostos ao benzeno. Acta Amazonica, v.36, n.3, p.357-364, 2006.

DISNER, G. R.; ROCHA, M. V.; MIRANDA, G. B.. Avaliação da atividade mutagênica do Roundup em Astyanax altiparanae (Chordata, Actinopterygii). Evidência, Joaçaba, v.11, n.1, p.33-42, 2011.

DUNBAR, J. C.; LIN, C.; VERGUCHT, I.; WONG, J.; DURANT, J. L.. Estimating the contributions of mobile sources of $\mathrm{PAH}$ to urban air using real-time PAH monitoring. Science of the Total Environment, v.279, p.1-19, 2001.

EISELE, G. R.. Naphthalene distribution in tissues of laying pullets, swine, and dairy cattle. Bull Environmental Contamination and Toxicology, v.34, p.549-556, 1985.
GARUTTI, V.; BRITSKI, H. A.. Descrição de uma espécie nova de Astyanax (Teleostei: Characidae) da bacia do alto Rio Paraná e considerações sobre as demais espécies do gênero na bacia. Anais. Comunicação Museu de Ciência e Tecnologia PUCRS - Série Zoologia, v.13, p.65-88, 2000.

GONTIJO, Á. M. M. C.; BARRETO, R. E.; SPEIT, G.; REYES, V. A. V.; VOLPATO, G. L.; SALVADORI, D. M. F.. Anesthesia of fish with benzocaine does not interfere with comet assay results. Mutation Research: Genetical Toxicology and Environmental Mutagenesis, v.534, p.165-172, 2003.

GUIMARÃES, E. T.; DOMINGOS, M.; ALVES, E. S.; CALDINI Jr, N.; LOBO, D.J.A.; LICHTENFELS, A.J.F.C.; SALDIVA, P.H.N.. Detection of the genotoxicity of air pollutants in the around the city of São Paulo (Brazil) with the Tradescnatiamicronucleus (Trad-MCN) assay. Environmental and Experimental Botany, v.22, p.1-8, 2000.

HEDDLE, J. A.. A rapid in vivo test for chromosome damage. Mutation Research, v.18, p.187-190, 1973.

HWANG, S.; CUTRIGHT, T. J.. Biodegradability of aged pyrene and phenanthrene in natural soil. Chemosphere, v.47, p.891899, 2002.

IARC. International Agency for Research on Cancer. Monographs on the evaluation of carcinogenic risks to human. Lyon: World Health Organization, 2002.

KAYAL, S. I.; CONNEL, D. W.. Occurrence and distribution of polycyclic aromatics hydrocarbons in surface sediments and water from the Brisbane river estuary. Estuarine, Coastal and Shelf Science, v.29, p.473-487, 1989.

LIMA, E. S.; SOUZA, S. R.; DOMINGOS, M.. Sensitivity of Tradescantia pallida (Rose) Hunt. 'Purpurea' Boom to genotoxicity induced by ozone. Mutation Research: Genetic Toxicology and Environmental Mutagenesis, v.675, p.41-45, 2009.

MA, T.. Tradescantia Micronucleus Bioassay and Pollen Tube Chromatid Aberration Test for in situ Monitoring and Mutagen Screening. Environmental Health Perspectives, v.37, p.85-90, 1981.

MEIRE, R. O.; AZEREDO, A.; TORRES, J. P. M.. Aspectos ecotoxicológicos hidrocarbonetos policíclicos aromáticos. Oecologia Brasiliensis, v.11, n.2, p.188-201, 2007. 
MELANCON, M. J.; LECH, J. J.. Distribution and elimination of naphthalene and 2-methylnaphthalene in rainbow trout during short and long-term exposures. Archives of Environmental Contamination and Toxicology, v.7, p.207220, 1978.

PACHECO, M.; SANTOS, M. A.. Biotransformation, endocrine and genetic responses of Anguilla Anguilla L. to petroleum destillate products and environmental contaminated waters. Ecotoxicology and Environmental Safety, v.49, n.1, p.64-75, 2001.

POTIN, O.; RAFIN, C.; VEIGNIE, E.. Bioremediation of an aged polycyclic aromatic hydrocarbons (PAHs)-contaminated soil by filamentous fungi isolated from the soil. International Biodeterioration and Biodegradation, v.54, n.1, p.45-52, 2004.

PRIOLI, S. M. A. P.; PRIOLI, A. J.; JÚLIO, H. F.; PAVANELLI, C. S.; OLIVEIRA, A. V.; CARRER, H.; CARRARO, D. M.; PRIOLI, L. M.. Identification of Astyanax altiparanae (Teleostei, Characidae) in the Iguaçu River, Brazil, based on mitochondrial DNA and RAPD markers. Genetics and Molecular Biology, v.25, p.421-430, 2002.

PUBLIC HEALTH SERVICE. Toxicological profile for naphthalene, 1-methylnaphtalene, and 2-

methylnaphthalene. U.S Department of health and human services. Agency for toxic substances and diseases registry, 2010.

RIBEIRO, L. R.. Teste do micronúcleo em medula óssea de roedores in vivo. In. RIBEIRO, L. R.; SALVADORI, D. M. F.; MARQUES, E. K.. Mutagênese ambiental. EdULBRA, 2003.

RODRIGUES, G. S.; MA, T. H.; PIMENTEL, D.; WEINSTEIN, L. H.. Tradescantia Bioassays as Monitoring Systems for Environmental Mutagenesis: a review. Critical Reviews in Plant Sciences, v.16, p.325-359, 1997.

SANTOS, A. P.; SEGURA-MUÑOZ, S. I.; NADAL, M.; SCHUHMACHER, M.; DOMINGO, J. L.; MARTINEZ, C. A.; MAGOSSO TAKAYANAQUI, A. M.. Traffic-related air pollution biomonitoring with Tradescantia pallida (Rose) Hunt. cv. Purpurea Boom in Brazil. Environmental Monitoring Assessment, v.187, 2015.

SAVÓIA, E. J. L.; DOMINGOS, M.; GUIMARÃES, E. T.; BRUMATI, F.; SALDIVA, P. H. N.. Biomonitoring genotoxic risks under the urban weather conditions and polluted atmosphere in Santo André, SP, Brazil, through Trad-MCN bioassay. Ecotoxicology and Environmental Safety, v.72, p.255-260, 2009.

SCHMID, W.. The micronucleus test. Mutation Research, v.31, p.9-15, 1975.

SCHULZ, U. H.; MARTINS-JÚNIOR, H.. Astyanax fasciatus as bioindicator of water pollution of Rio dos Sinos, RS, Brazil. Brasilian Journal of Biology, v.61, n.4, p.615-622, 2001.

SMITH, J. D.; BAGG, J.; WRIGLEY, I.. Extractable polycyclic hydrocarbons in water from rivers in southeastern Australia. Water Research, v.25, p.1145-1150, 1991.

TAVARES-DIAS, M.; MORAES, F.R.. Hematologia de peixes teleósteos. Ribeirão Preto: M. Tavares-Dias, 2004.

TRUSCOTT, B.; IDLER, D.; FLETCHER, G.. Alteration of reproductive steroids of male winter flounder (Pleuronectes americanus) chronically exposed to low levels of crude oil in sediments. Canadian Journal of Aquatic Science, v.49, p.2190-2195, 1992.

UEDA, T.; HAYASHI, M.; OHTSUKA, Y.; NAKAMURA, T.; KOBAYASHI, J.; SOFUNI, T.. A preliminary study of the micronucleus test by acridine Orange fluorescent staining compared with chromosomal aberrations test using fish erythropoietic and embryonic cells. Water Science Technology, v.25, p.235-240, 1992.

VARANASI, U.; UHLER, M.; STRANAHAN, S. I.. Uptake and release of naphthalene and it's metabolites in skin and epidermical mucus of salmonids. Toxicology Applied Pharmacology, v.44, p.277-289, 1978.

VIJAYAVEL, K.; GOMATHI, R. D.; DURGABHAVANI, K.; BALASUBRAMANIAN, M. P.. Sublethal effect of naphthalene on lipid peroxidation and antioxidant status in the edible marine crab Scylla serrata. Marine Pollution Bulletin, v.48, p.429-433, 2004.

WINTER, M. J.; ELLIS, L. C. J.; HUTCHINSON, T. H.. Formation of micronuclei in erythrocytes of the fathead minnow (Pimephales prometas) after acute treatment with mitomycin C or cyclophosphamide. Mutation ResearchGenetic Toxicology and Environmental Mutagenesis, v.629, n.2, p.89-99, 2007.

WRIGHT, D. A.; WELBOURN, P.. Environmental Toxicology. New York: Cambridge University Press, 2002. 